\title{
Fresenius Biotech
}

National Cancer Institute

\section{Source}

National Cancer Institute. Fresenius Biotech. NCI Thesaurus. Code C124044.

A German company that researches, develops, and markets biopharmaceuticals for the treatment of severe diseases. 